\title{
Comparing Voice-Only And Video Interviews In A Practical English Classroom At A Korean University
}

Chris Kobylinski, Hanguk University of Foreign Studies, Korea

\begin{abstract}
This paper explores why the use of video interviews in the classroom can be advantageous to voice-only interviews. The researcher documented the improvement in student motivation and listening comprehension when students watched interviews versus listening to them on the same subject matter.
\end{abstract}

Keywords: EFL Listening Activities; Listening Comprehension; Motivation; Videos; Voice-Only Recordings

\section{RESEARCH PROBLEM AND BACKGROUND}

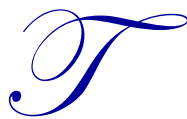

he researcher's university has been using the Academic Listening Encounters series of books for the past two years in its freshmen Practical English classes. For the most part, the instructor enjoyed using the text as the primary source for the class. There are usually three listening sections in each chapter and all of the listening activities are voice-only recordings played on CDs or as MP3 files. The first activity is usually short, very topical and enjoyed by most students. The last activity is always an academic lecture and, although not always enjoyed by the students, it is helpful in providing information in an academic setting.

The second section is a series of interviews with various individuals and is designed to provide a personal and cultural perspective for the students. Although the researcher had initially thought that this section would be interesting and beneficial for the students, he noticed, through observation and course feedback, that the students found most of the interviews to be boring and irrelevant. In addition to the lack of motivation, the interviews seemed to give the students trouble in terms of listening comprehension. Each set of interviews was prefaced by a vocabulary list and followed by a series of listening comprehension questions. In some sections, the questions are true or false questions and in other sections, they are multiple choice questions. The researcher noticed that the students often answered the questions having to do with feelings or emotions incorrectly. As a result, he considered the possibility that the current form of voice-only recordings may have had a direct influence upon the observed lack of motivation and comprehension.

\section{RESEARCH QUESTION}

Would using videos instead of voice-only recordings improve student motivation and comprehension and thus be the best medium for introducing students to the targeted language goals currently expected by the university?

\section{LITERATURE REVIEW}

The researcher believes that the use of videos in the classroom would the most popular and beneficial medium for increasing student motivation and learning in the classroom. Moreover, current research has shown that videos do provide more motivation. Wang (2011) observed that "The most popular CD ROM feature was "video of real-life conversations' which demonstrates, again, student's desire for training of communication skill." If the students are more interested in video format, would they be more motivated and listen with greater purpose? 
According to Baltova (1994), "students in the sound-only conditions in the two experiments were less successful in maintaining the interest and concentration in listening." Ur (1984) also contended that the use of voiceonly recordings was something that we should reconsider in the classroom; "If the speaker is usually present in reallife listening situations, towards which we wish to train our students in the classroom, then perhaps we should think again about how much we ought to use live recordings as the basis of our exercises." Moreover, the benefits of using video in the classroom as a form of motivation has been well documented. Sherman (2003) stated that "The eye is caught, and this excites interest in the meaning of the words. Authenticity itself is an inducement - there is a special thrill in being able to understand and enjoy the real thing. In addition, video is today's medium." If video "catches the eye" and motivates the student, does it have a distinct advantage over a voice over recording? There seems to be evidence that supports that the video provides a more realistic, and therefore better, representation of the real world. "There is an obvious appeal to using video in the language classroom. Instead of the rather unnatural task of listening to a disembodied voice emanating from an audio player, learners are able to see the speaker and elements of the surrounding environment. Video is thus a "multi-sensory medium" (Swaffar \& Vlatten, 1997). In addition to the motivational factor, could video provide the L2 student with other additional benefits? Rhodes (2003) points out that "Videos provide children with much-needed interactive listening activities, a view of aspects of the culture that they wouldn't have an opportunity to learn about in the classroom, language models with a variety of regional or national accents, and the visual reinforcement of concepts learned in class." Burt (1999) further states that "Videos are a powerful tool in helping English language learners improve their language skills. They provide the learner with content, context, and language." Besides providing additional motivation to the students, video gives the students a distinct advantage by allowing them to see the speaker. "Video brings us all kinds of voices in all kinds of situations, with full contextual back-up."

One obvious advantage for comprehension is the visual dimension, particularly for pragmatic understanding in dialogue" (Sherman, 2003, p. 2). This visual dimension allows the L2 to listen to the interview in a more practical and life-like setting. "On the other hand, as we have seen, the speaker is actually visible to the listener in most real-life situations and his facial expression and movements provide some material aids to comprehension, so that it does not seem right to constantly deprive the learner of his presence in classroom exercises" (Ur, 1984, p. 25). The visual element of the videos might also offer one more advantage - it may allow the students to more accurately gauge the emotional response of the speaker. As previously stated, the L2 students often misjudged the feelings and emotions of the speaker. Could the video help the students to gauge the emotional response and feelings of the speaker? Previous studies have suggested that videos may. "By several intensive subjective evaluation studies we found that human beings recognize anger, happiness, surprise and dislike by their visual appearance, compared to voice-only detection" (DeSilva, 1997). If the videos are more interesting to the students, would they be more attentive to them; and if videos allow the L2 a better opportunity to understand emotion, would the students be better equipped to answer questions dealing with emotions and feelings? The researcher believes the answer to both of these questions is yes. The videos will motivate the students to listen carefully and the visual clues in the videos will further aid their listening comprehension. "There is no denying the fact that video is a classroom resource and it can be used or should be used to light up the classroom whenever necessary" (John, 2010, p. 28).

\section{Subjects}

The subjects of this descriptive study were students from four of the researcher's Practical English Classes. Each class size ranged from 20 to 25 students. The level of the students ranged from fluent to lower intermediate. Some students had studied and/or lived abroad for extended periods of time and some had little or no confidence in their English language ability; many fell in the category of upper intermediate and had a good grasp of English and of academic language in their native Korean language. The ages of the students ranged from 18 to 26 . The students of the classes may not have been reflective of the average Korean university, but they were, for the most part, a good cross section of the students taking Practical English at the researcher's university.

\section{Apparatus of Instrumentation}

The students were given a pre and post-task survey and also completed five multiple choice questions based on the interviews. The surveys provided both quantitative data and qualitative feedback and the multiple choice questions provided quantitative data. The surveys attempted to see if the students had a perceived - and later, 
an actual - preference for one format based on enjoyment and benefit. The multiple choice questions contained one involving emotion or feeling. The voice-only interview came from the Academic Listening Encounters CD and the video was made by the instructor. Both interviews were authentic. The voice-only interview may be seen by some as semi-scripted and the video was done without any script. The interviews all began with the same questions; however, the follow-up questions differed slightly based on the interviewee's responses. The time of both interviews was very similar to avoid a bias. The subject of the voice-only interviews was an American living in America and the subject of the video interview was a native English speaker living in South Korea. The style of the video showed only the face and body of the interviewee, which the researcher believed was beneficial for a few reasons. First, it is more realistic as this is the style often seen in video chatting. If a student was speaking with someone via a video chatting program, they would see a similar view. Also, the researcher believed it would allow the students to focus on the interviewee and provide them with a form of modeling.

\section{Procedure}

In this descriptive study, the students experienced both voice-only and video interviews on the same topic. The students were given a pre-task survey, multiple choice questions for each interview and a post-task survey. Two of the classes listened to the voice-only recording first and two classes watched the video interview first.

The purpose of the pre and post-task surveys was to gauge the L2 students' motivation and feelings towards both formats of interviews. The purpose of the multiple choice questions was to gauge the L2 students' listening comprehension. The researcher looked at the pre-task surveys to see if the students thought they would enjoy one format more than the other and if they thought one format would be more beneficial. The post-task survey asked the students if they did enjoy one format more and if one format was more beneficial. The multiple choice questions contained one involving emotion or feelings and the researcher scored the questions to see if there was any difference in the overall comprehension or the question about the interviewee's emotions or feelings.

The researcher believed the students would show a preference for the videos in the pre and post-task surveys and that they would score higher on the questions from the video. The researcher believed the students would be more motivated by the video and that the increase of motivation, along with the added visual clues, would aid in their comprehension.

\section{Data Collection}

After completion of the activity, the researcher collected the surveys and questions and the surveys were analyzed to see if there was a perceived or actual preference for one form. The pre-task survey was analyzed to see if there was a perceived preference and the post-task survey was analyzed to see if there was an actual preference. The researcher also asked why the students chose one over the other and made notes of any responses that were given. The multiple choice questions were scored to see if there was a difference in listening comprehension. If a wrong answer was circled or if the question wasn't answered, it was marked as incorrect.

\section{DATA ANALYSIS AND FINDINGS}

Ninety-two students received the surveys and questions and all 92 completed them. The high rate of participation was due to the fact that all students gave their informed consent and because the research took place during class. Although all students completed the survey and questions, not all of them gave qualitative feedback when asked why they preferred one form over the other.

\section{Quantitative Data}

In the pre-task survey, $52.17 \%$ of the 92 students indicated that they thought they would enjoy the videos more, compared to $47.83 \%$ for the voice-only recording. In the post-task survey, $76.1 \%$ of the students indicated that they enjoyed the videos more compared to $23.9 \%$ for the voice-only. In response to the pre-task question about which form would be more beneficial, 58.7 percent of the students thought the voice-only would be more beneficial compared to $41.3 \%$ for the videos. The post-task survey indicated a shift, as $64.13 \%$ of the students said the videos were more beneficial, compared to $35.87 \%$ for the voice-only recordings. 
The data for the multiple choice questions showed that the mean for the voice-only task was 4.28 with a $\sigma$ of .958 and the mean for the video task was 4.54 with a $\sigma$ of .752. In regard to the question dealing with emotion of feeling, $74 \%$ of the students answered it correctly for the voice-only activity, compared to $79.35 \%$ for the video activity.

\section{Qualitative Feedback}

Of the students who said that they thought the video was more beneficial, the most common reason given was because it was more realistic. Surprisingly, the most common reason given amongst students who thought the voice-only was more beneficial was that voice-only is the style that appears on standardized tests.

\section{Relevance of Research to Education}

The use of voice-only recordings has been, and still is, a staple in many EFL classrooms. These recording offer many benefits and are very common in standardized testing. However, the researcher would like to point out the validity of using videos, especially for activities that involve interviews and in classes that want to focus on practical English. The research showed that students enjoy the videos more and believe that they are more beneficial and therefore will be more motivated to watch them. Also, the data suggests that students will use visual clues from the videos that will help with their comprehension, especially in terms of judging emotional reactions. Using videos may not be appropriate for all classes, especially those that focus on test preparation, but they can be helpful in exposing students to more realistic listening situation. The researcher doesn't believe that videos should completely replace voice-only recordings; rather, they should be used in conjunction with the voice-only recordings to give the students a variety of listening practice opportunities.

\section{Note on Limitations}

This descriptive study has many limitations. It involves the use of a pre-existing course and pre-existing book. The subjects of the voice-only interviews are different from the subjects of the video interviews, but the topics and the initial questions are the same. Also, the students have already experienced the CD interviews and may be more comfortable with them or may be bored of the format. This study isn't flawless, yet the author believes it will adequately show the merits of video over voice-only recordings and will lead to future research by the researcher.

\section{ACKNOWLEDGEMENT}

This work was supported by Hankuk University of Foreign Studies Research Fund of 2013.

\section{AUTHOR INFORMATION}

Chris Kobylinski has taught Practical English at Hanguk University of Foreign Studies in Seoul, South Korea, for the past six years. Practical English is a 4-skills course designed to prepare first-year University students from nonEnglish majors for future university classes taught in English. He obtained his B.A. in English from the College of the Holy Cross and his M.Ed (TESOL) from Framingham State University. E-mail: chriskoby@gmail.com

\section{REFERENCES}

1. Baltova, I. (1994). Impact of video on the comprehension skills of core French students. Canadian Modern Language Review, 50(3), 506-531.

2. Burt, M. (1999). Using videos with adult english language learners. ERIC Digest. (ED434539).

3. De Silva, L. C., Miyasato, T., Nakatsu, R. (1997). Facial emotion recognition using multi-modal information. Proceedings of 1997 International Conference on Information, Communications and Signal Processing (ICICS).

4. John, D. (2010). Reinforced language tasks using video. Modern English Teacher, 19(2).

5. Sanabria, K. (2004). Academic listening encounters. Cambridge: Cambridge University Press. 
6. Sherman, J. (2003). Using authentic video in the language classroom. Cambridge: Cambridge University Press.

7. Swaffar, J., \& Vlatten, A. (1997). A sequential model for video viewing in the foreign language curriculum. Modern Language Journal, 81(1), 175-188.

8. Rhodes, N., \& Pufal, I. (2003). Teaching foreign languages to children through video. Centre for Applied Linguistics. Retrieved from http://www.cal.org/resources/Digest/0310pufahl.html

9. Ur, P. (1984) Teaching listening comprehension. Cambridge: Cambridge University Press.

10. Wang, P.-L. (2011). The effects of computer-assisted whole language instruction on Taiwanese university students' English learning. English Language Teaching, 4(4). 


\section{NOTES}

